\title{
Long-acting FC-fusion rhGH (GX-H9) shows potential for up to twice-monthly administration in GH-deficient adults
}

\author{
Cheol Ryong Ku', Thierry Brue², Katharina Schilbach3', Stanislav Ignatenko4, Sandor Magony5, \\ Yoon-Sok Chung ${ }^{6}$, Byung-Joon Kim ${ }^{7}$, Kyu Yeon Hur ${ }^{8}$, Ho-Cheol Kang ${ }^{9}$, Jung Hee Kim ${ }^{10}$, Min Seon Kim ${ }^{11}$, \\ Aldona Kowalska ${ }^{12}$, Marek Bolanowski ${ }^{13}$, Marek Ruchala ${ }^{14}$, Svetozar Damjanovic ${ }^{15}$, Juraj Payer ${ }^{16}$, \\ Yun Jung Choi ${ }^{17}$, Su Jin Heo ${ }^{17}$, Tae Kyoung Kim ${ }^{18}$, MinKyu Heo ${ }^{18}$, Joan Lee ${ }^{18}$ and Eun Jig Lee ${ }^{1}$
}

${ }^{1}$ Endocrinology, Department of Internal Medicine, Yonsei University College of Medicine, Seoul, Republic of Korea, ${ }^{2}$ Aix-Marseille Université, INSERM U1251, Marseille Medical Genetics, and AP-HM, Hôpital Conception, Marseille, France, ${ }^{3}$ Medizinische Klinik und Poliklinik IV, Klinikum der Universität München, Munich, Germany, ${ }^{4}$ Charité Research Organisation, Berlin, Germany, ${ }^{5}$ First Department of Medicine, University of Szeged, Szeged, Hungary, ${ }^{6}$ Department of Endocrinology and Metabolism, Ajou University School of Medicine, Suwon, Republic of Korea, ${ }^{7}$ Gachon University Gil Medical Center, Incheon, Republic of Korea, ${ }^{8}$ Samsung Medical Center, Seoul, Republic of Korea, ${ }^{9} \mathrm{Chonnam}$ National University Hwasun Hospital, Hwasun-gun, Republic of Korea, ${ }^{10}$ Seoul National University Hospital, Seoul, Republic of Korea, ${ }^{11}$ Asan Medical Center, Seoul, Republic of Korea, ${ }^{12}$ Endocrinology Clinic Holycross Cancer Centre, Swietokrzyskie, Poland, ${ }^{13}$ Department of Endocrinology, Diabetes and Isotope Therapy, Wroclaw Medical University, Wroclaw, Poland, ${ }^{14}$ Poznan University of Medical Sciences Chair and Department of

Endocrinology, Metabolism and Internal Medicine, Poznań, Poland, ${ }^{15}$ Clinical Center of Serbia, Belgrade, Serbia, ${ }^{16} 5$ th Department of Internal Medicine, Comenius University Faculty of Medicine, University Hospital, Bratislava, Slovakia, ${ }^{17}$ Handok Inc., Seoul, Republic of Korea, and ${ }^{18}$ Genexine Inc., Seongnam, Republic of Korea

\begin{abstract}
Objective: Hybrid Fc-fused rhGH (GX-H9) is a long-acting recombinant human growth hormone (GH) under clinical development for both adults and children with GH deficiency (GHD). We compared the safety, pharmacokinetics and pharmacodynamics of weekly and every other week (EOW) dosages of GX-H9 with those of daily GH administration in adult GHD (AGHD) patients.

Design: This was a randomized, open-label, active-controlled and dose-escalation study conducted in 16 endocrinology centers in Europe and Korea.

Methods: Forty-five AGHD patients with or without prior GH treatment were enrolled. Patients with prior GH treatments were required to have received the last $\mathrm{GH}$ administration at least 1 month prior to randomization. Subjects were sequentially assigned to treatment groups. Fifteen subjects were enrolled to each treatment group and randomly assigned to receive either GX-H9 or Genotropin (4:1 ratio). GX-H9 dosage regimens for Groups 1, 2 and 3 were $0.1 \mathrm{mg} / \mathrm{kg}$ weekly, $0.3 \mathrm{mg} / \mathrm{kg}$ EOW and $0.2 \mathrm{mg} / \mathrm{kg}$ EOW, respectively. All Genotropin-assigned subjects received $6 \mu \mathrm{g} / \mathrm{kg}$ Genotropin, regardless of treatment group. Main outcome analyses included measurements of serum insulinlike growth factor 1 (IGF-I), safety, pharmacokinetics, pharmacodynamics and immunogenicity. Results: Mean GX-H9 peak and total exposure increased with an increase in dose after a single-dose administration. The mean IGF-I response was sustained above baseline over the intended dose interval of $168 \mathrm{~h}$ for the weekly and $336 \mathrm{~h}$ for the EOW GX-H9 groups. Safety profiles and immunogenicity were not different across the treatment groups and with Genotropin.
\end{abstract}

Conclusions: GX-H9 has the potential for up to twice-monthly administration.

(C) 2018 European Society of Endocrinology Printed in Great Britain
Published by Bioscientifica Ltd. 


\section{Introduction}

Adult growth hormone deficiency (AGHD) is a recognized clinical syndrome associated with numerous metabolic abnormalities, including abnormal body composition, reduced physical performance, altered lipid metabolism, decreased bone mass, increased insulin resistance and reduced quality of life $(1,2,3)$. Most metabolic abnormalities associated with AGHD can be reversed with recombinant human GH (rhGH) replacement (4). Traditional GHD treatment includes the use of daily subcutaneous (sc) injections of rhGH. However, this schedule is too frequent to be convenient for many patients, raising concerns about poor adherence to treatment, which can lead to reduced efficacy (5). Longacting rhGH preparations not only allow less frequent injections, but also improve compliance by reducing the inconvenience of daily injections and potentially contribute to improving the efficacy of GH treatment $(6,7,8)$.

GX-H9 is a novel extended long-acting rhGH fused to hybrid Fc (hyFc). The hyFc consists of human immunoglobulin D (IgD) and human immunoglobulin G4 (IgG4), and its fusion to hGH expands the size of GX-H9, which increases the half-life of GX-H9 by reducing renal clearance. IgG4 further increases the half-life of GX-H9 via neonatal Fc receptor-mediated endocytosis and recycling of the Fc-fusion protein $(9,10,11)$. Extension of the half-life was initially observed in non-clinical studies performed in rats (unpublished internal data) and was also proven in a Phase 1 study of healthy volunteers. GX-H9 was safe and well tolerated in healthy adults, and adverse event profiles were similar to those of daily GH treatments (unpublished internal data). GX-H9 is in the Phase 2 stage of clinical development based on currently available non-clinical and clinical study results, paving its way as a possible option for GH treatment that is more convenient with less frequent injections.

The purpose of this study was to assess serum insulinlike growth factor 1 (IGF-I), together with safety, tolerability, pharmacokinetics (PK) and pharmacodynamics (PD) of weekly and EOW dosages of extended long-acting antibody-fused rhGH (GX-H9) in the treatment of AGHD.

\section{Subjects and methods}

\section{Subjects}

Men and women (between the ages of 20 and 65 years) who were diagnosed with either adult- or childhood-onset
GHD were enrolled in this study. Patients with prior GH treatments were required to have received the last GH administration at least 1 month prior to randomization.

Inclusion criteria were as follows: confirmed AGHD by 1 or more GH stimulation tests (peak GH less than 3.0 ng/ $\mathrm{mL}$ in insulin tolerance test or less than $4.0 \mathrm{ng} / \mathrm{mL}$ in GH releasing hormone (GHRH) combined with arginine stimulation test) (12), stable hormone replacement therapies for other deficient hypothalamic-pituitary axes for at least 3 months before screening, an IGF-I standard deviation (s.D.) less than -1, BMI between 18.0 and $35.0 \mathrm{~kg} /$ $\mathrm{m}^{2}$, negative result for anti-rhGH antibodies, agreement with appropriate contraceptive methods during the study and for 6 months after the last dose of study drug and a negative serum pregnancy test result.

Exclusion criteria were as follows: evidence of intracranial tumor growth within the last 12 months, hematologic diseases or malignancies, intracranial hypertension, glycated hemoglobin (HbA1c) equal or greater than $7.0 \%$, impaired liver or kidney function indicated by aspartate transaminase/alanine transaminase $>2$ times the upper limit of normal (ULN) or serum creatinine $>1.5$ times the ULN, active acromegaly within 18 months or Cushing's syndrome within 12 months before screening, systemic corticosteroids other than replacement therapy within 3 months before screening and any medical condition that might pose a risk and confound the results.

\section{Trial design and protocol}

This study was conducted at 16 endocrinology centers in seven countries, including France, Serbia, Hungary and Slovakia (1 site in each country); Germany (2 sites); Poland (3 sites) and Republic of Korea (7 sites).

This was a Phase $1 \mathrm{~b} / 2$, randomized, active-controlled, open-label, sequential dose group study designed to assess the safety, PK and PD of weekly and EOW dosages of GX-H9 in the treatment of AGHD. The study consisted of four periods, including a washout period (1 month; applicable only for previously daily GH-treated subjects), screening visit, treatment period (12 weeks) and follow-up visit ( 28 days after the last dose). The study was approved by the Institutional Review Boards of Ajou University Hospital, Severance Hospital, Gachon University Gil Medical Center, Samsung Medical Center, Chonnam National University Hwasun Hospital, Seoul National University Hospital, Asan Medical Center, CPP 
Sud-Méditerranée 1, Ethikkommission der Medizinische Fakultät der LMU München, Egeszsegugyi Tudomanyos Tanacs Klinikai Farmakologiai Etikai Bizottsaga, Komisja Bioetyczna przy Uniwersytecie Medycznym we Wrocławiu and Local Ethics Committee of Clinical Centre Serbia. Before any study activity, written informed consent was obtained from the subjects. The study was performed in accordance with ethical principles having their origin in the Declaration of Helsinki (2013, 7th revision), the International Council for Harmonisation (ICH E6 (R1)) and all applicable regulations. The ClinicalTrials.gov identifier is NCT02946606 and EudraCT number is 2014002698-13.

Subjects who met all the inclusion criteria and none of the exclusion criteria were enrolled in the study. Subjects were sequentially assigned to study treatments starting with Group 1. Fifteen subjects were assigned to each treatment group and were randomly assigned to receive either GX-H9 or Genotropin at a ratio of 4:1. Before proceeding to the next group, safety and IGF-I level data were reviewed by the safety monitoring committee (SMC) and the decision to proceed to the next group was only made if the previous lower dose was found to be safe and well tolerated.

After SMC review of data from Groups 1 and 2, the protocol was amended to change the Group 3 dosage regimen from $0.6 \mathrm{mg} / \mathrm{kg}$ EOW to $0.2 \mathrm{mg} / \mathrm{kg}$ EOW (Fig. 1).

The randomized subjects were hospitalized the day before the first and last administration of the study drug and remained hospitalized until $24 \mathrm{~h}$ after the study drug was administered (Week 1, Day 2 and Week 11/12, Day 2) for full PK and PD (i.e. IGF-I and IGF binding protein-3 (IGFBP-3)) sample collection. For other visits, PD samples were collected on Day 4 (72h after dosing) to measure peak IGF-I levels.

Antibodies to rhGH were assessed for all subjects at the screening visit; antibodies to GX-H9 were only assessed in the GX-H9 group on Day 1 (before study drug dosing), Day 32 (Week 5) and at the follow-up visit. Laboratory safety evaluations were performed during Weeks 1, 3, 5, 9 and 11.

\section{Safety, pharmacokinetics and pharmacodynamics}

Safety assessments included vital signs, physical examinations, electrocardiogram, laboratory safety evaluation, immunogenicity of GX-H9, injection-site reactions and immunogenic responses. The laboratory safety evaluation included routine hematology and serum biochemistry, glucose and lipid parameters and hormonal (thyroid and adrenal) status assessments. Adrenal function was assessed at each study site. If the morning cortisol levels were above $14.5 \mu \mathrm{g} / \mathrm{dL}$ or peak cortisol was above $18 \mu \mathrm{g} / \mathrm{dL}$ during the insulin tolerance and adrenocorticotropic hormone (ACTH) stimulation tests, adrenal function was regarded as normal. Determinations of anti-hGH in human serum were performed and validated at the Universitätsklinikum Leipzig, ILM, Germany. The radio-precipitation assay (RPA) for determining anti-hGH antibodies was validated with a statistical-based approach according

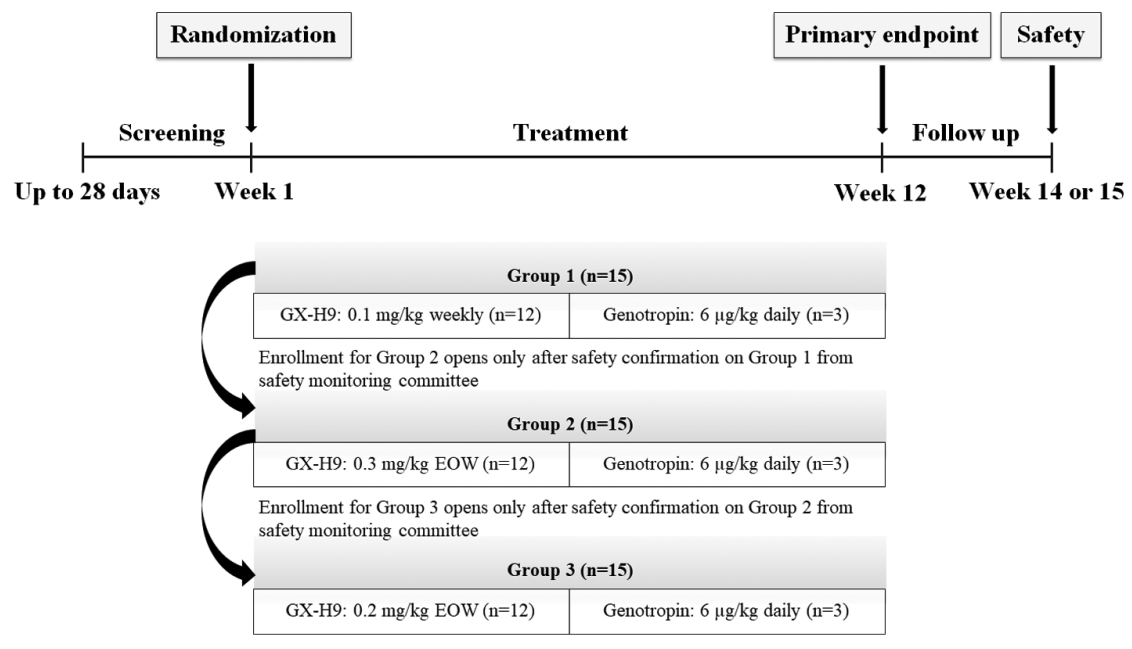

\section{Figure 1}

Overall study design. Each group consisted of different subjects. After confirming an absence of safety issues, administration of GX-H9 at the applicable doses proceeded. EOW, every other week. 
Table 1 Demographics and baseline characteristics (intent-to-treat set).

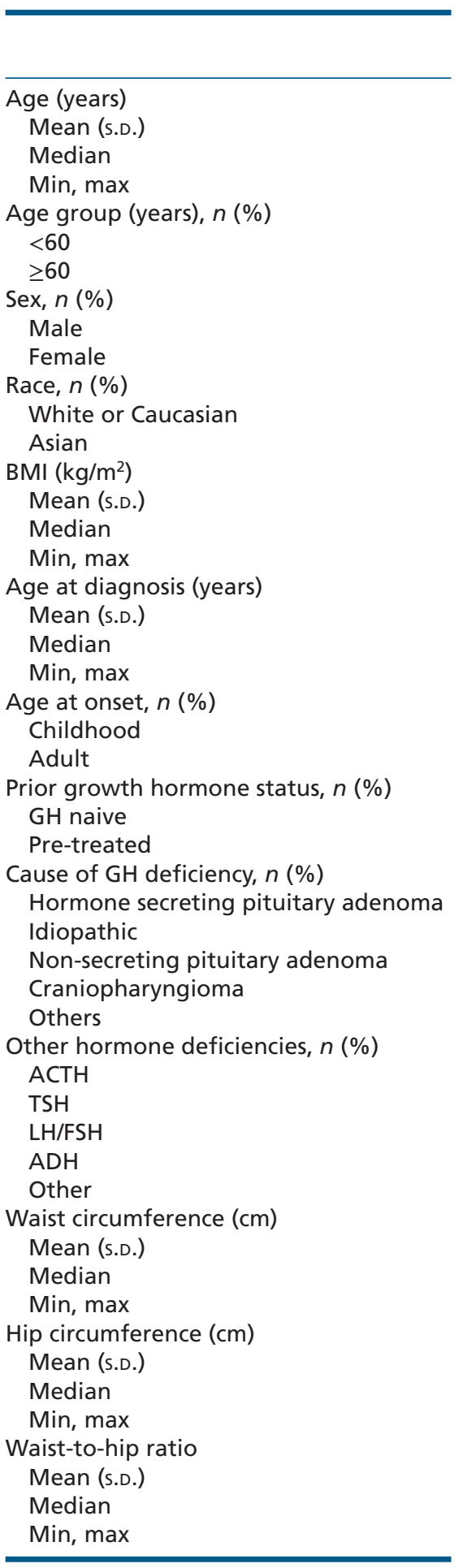

\begin{tabular}{c}
\hline $\begin{array}{c}0.1 \mathrm{mg} / \mathbf{k g} \text { GX-H9 } \\
\text { weekly }(n=11)\end{array}$ \\
\hline
\end{tabular}

$43.1(12.28)$
47.0

27,60

$10(90.9)$

1 (9.1)

$8(72.7)$

3 (27.3)

0

$11(100.0)$

$25.437(4.4726)$
23.846
$19.71,34.03$

$$
\begin{gathered}
37.8(15.70) \\
46.0
\end{gathered}
$$

15,59

1 (9.1)

$10(90.9)$

0
$11(100.0)$

3 (27.3)

2 (18.2)

1 (9.1)

4 (36.4)

1 (9.1)

9 (81.8)

9 (81.8)

$10(90.9)$

5 (45.5)

4 (36.4)

$89.10(9.830)$

84.00

$79.5,108.0$

98.95 (7.663)

98.00

$88.9,113.0$

$0.899(0.0532)$

0.910

$0.83,1.03$

\begin{tabular}{c}
$0.3 \mathrm{mg} / \mathbf{k g}$ GX-H9 \\
EOW $(n=12)$ \\
\hline
\end{tabular}

43.3 (13.68)

41.5

22,64

$10(83.3)$

2 (16.7)

8 (66.7)

4 (33.3)

$6(50.0)$

$6(50.0)$

$25.278(4.6417)$
25.492
$18.61,34.03$

$29.2(19.55)$

29.0

3,54

5 (41.7)

7 (58.3)

5 (41.7)

7 (58.3)

0

2 (16.7)

4 (33.3)

1 (8.3)

5 (41.7)

8 (66.7)

$8(66.7)$

$12(100.0)$

4 (33.3)

1 (8.3)

89.67 (10.984)

89.50

$72.0,105.0$

97.88 (7.075)

98.00

$86.0,112.5$

$0.914(0.0728)$

0.905

$0.82,1.06$

0.2 mg/kg GX-H9
EOW $(n=12)$

\begin{tabular}{c}
$\begin{array}{c}\mathbf{6} \boldsymbol{\mu g} / \mathbf{k g} \text { Genotropin } \\
\text { daily }(n=9)\end{array}$ \\
\hline $35.4(13.65)$ \\
35.0 \\
21,66 \\
$8(88.9)$ \\
$1(11.1)$ \\
$7(77.8)$ \\
$2(22.2)$ \\
$6(66.7)$ \\
$3(33.3)$
\end{tabular}

23.311 (3.0634)

23.306

$18.46,30.10$

26.114 (4.5013)

26.472

$19.29,32.86$

$$
\begin{gathered}
41.2(11.38) \\
41.5 \\
25,63
\end{gathered}
$$

$26.0(17.56)$

21.0

9,59

0
$12(100.0)$

4 (44.4)

5 (55.6)

2 (16.7)

10 (83.3)

1 (11.1)

8 (88.9)

$3(25.0)$

$1(8.3)$

7 (58.3)

0

1 (8.3)

8 (66.7)

$10(83.3)$

11 (91.7)

3 (25.0)

4 (33.3)

1 (11.1)

1 (11.1)

1 (11.1)

1 (11.1)

5 (55.6)

8 (88.9)

$9(100.0)$

$9(100.0)$

4 (44.4)

1 (11.1)

84.54 (10.857)

86.00

93.74 (9.718)

96.00

$70.0,100.0$

$80.0,109.0$

94.17 (4.634)

94.75

87.0, 103.0

102.72 (11.998)

103.00

87.0, 121.0

$0.894(0.0855)$

0.905

$0.913(0.0387)$

0.900

$0.80,1.03$

$0.86,1.00$

ACTH, adrenocorticotropic hormone; ADH, antidiuretic hormone; EOW, every other week; GH, growth hormone; LH/FSH, luteinizing hormone/folliclestimulating hormone; Max, maximum; Min, minimum; $N$, total number of subjects for each treatment group; TSH, thyroid-stimulating hormone.

to the recommendations of the United States Food and Drug Administration (U.S. FDA) and Shankar et al. (13, 14). Anti-GX-H9 antibodies were quantified using an enzyme-linked immunoassay (ELISA) method validated by Intertek Pharmaceutical Services (Manchester, UK). If binding antibodies were detected, neutralizing 


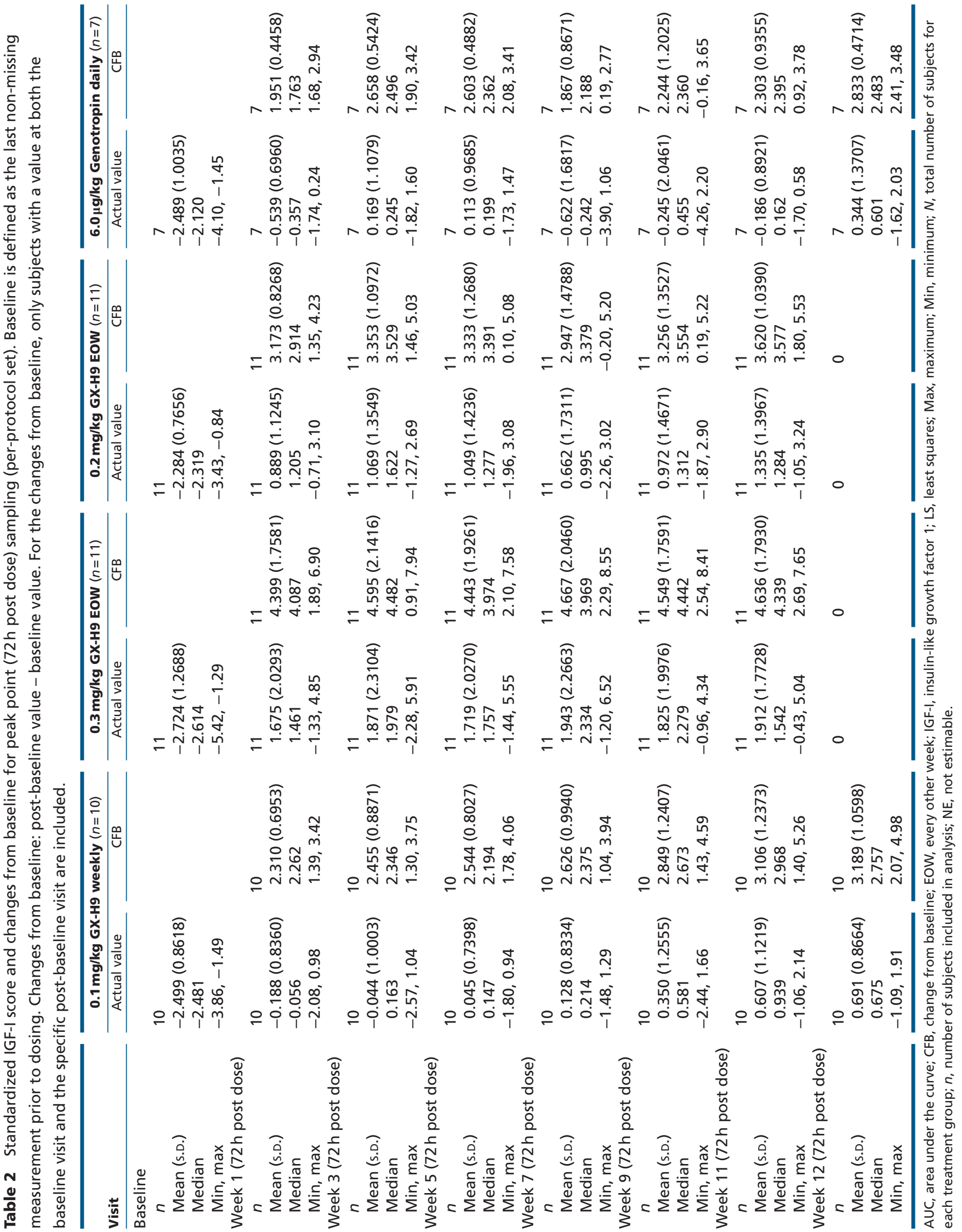




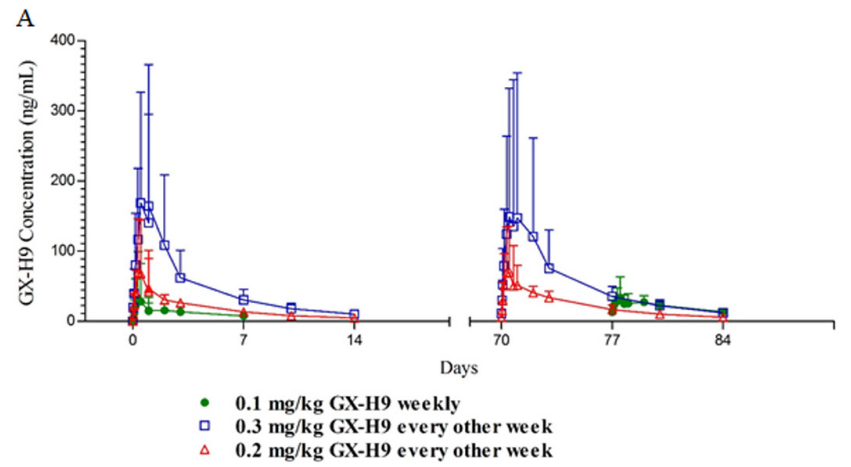

antibodies were to be determined by a cell-based functional assay and substituting the hGH agonist in the assay with the GX-H9 analog, with measurements repeated after 3 months at the follow-up visit.

PK analyses were performed at Intertek Pharmaceutical Services. The PK parameters were calculated using a noncompartmental approach with Phoenix WinNonlin version 6.4 (Certara USA, Inc., Princeton, NJ, USA). PD analyses of the serum, including IGF-I and IGFBP-3, were performed at Endocrine Research Laboratory (Munich, Germany) using an iSYS assay (15). PD parameters were derived using a

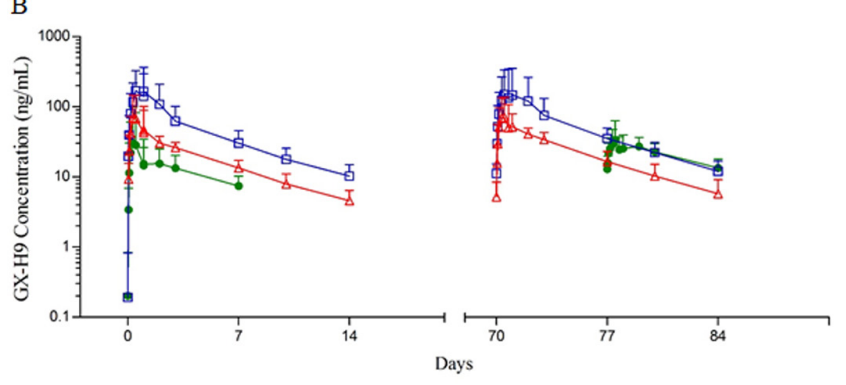

- $0.1 \mathrm{mg} / \mathrm{kg} \mathrm{GX}-\mathrm{H} 9$ weekly

$0.3 \mathrm{mg} / \mathrm{kg} \mathrm{GX}-\mathrm{H} 9$ every other wee

$\Delta \quad 0.2 \mathrm{mg} / \mathrm{kg} \mathrm{GX}-\mathrm{H} 9$ every other week

\section{Figure 2}

Serum concentrations of GX-H9 in the per-protocol set. The data are expressed as means \pm standard deviations with linear and semilogarithmic scales. (A) A linear scale is shown, and $(B)$ a semilogarithmic scale is shown. noncompartmental method and included the observed maximum serum concentration $\left(C_{\max }\right)$ and area under the serum concentration-time curve from time 0 to the last measurable concentration $\left(\mathrm{AUC}_{0-t}\right)$.

\section{Endpoints}

The primary endpoint of this study was the change in serum IGF-I levels in relation to time and dose strengths compared to daily rhGH. Secondary efficacy endpoints included actual values and changes from baseline lipid parameters, waist/hip circumference and BMI at Week 12. PK, PD and safety parameters were considered as other secondary endpoints.

Table 3 Geometric mean serum pharmacokinetic parameters of GX-H9 (per-protocol set). Values are reported with the coefficient of variation in parentheses, unless otherwise noted. $\mathrm{AUC}_{0 \text {-tau }}$ was calculated over $168 \mathrm{~h}$ for the $0.1 \mathrm{mg} / \mathrm{kg} \mathrm{GX}-\mathrm{H} 9 \mathrm{weekly}$ dosing group and over $336 \mathrm{~h}$ for the 0.3 and $0.2 \mathrm{mg} / \mathrm{kg}$ GX-H9 EOW dosing groups. For ease of presentation, the Week 11 visit for $0.3 \mathrm{mg} / \mathrm{kg}$ and $0.2 \mathrm{mg} / \mathrm{kg} \mathrm{GX}-\mathrm{H} 9 \mathrm{EOW}$ is presented with the Week 12 visit.

\begin{tabular}{|c|c|}
\hline Parameters (unit) & 0.1 mg/kg GX-H9 weekly $(n=10)$ \\
\hline \multicolumn{2}{|l|}{ Week 1} \\
\hline $\mathrm{AUC}_{0 \text {-inf }}(\mathrm{h} * \mathrm{ng} / \mathrm{mL}), n$ & 3179 (54.7), 5 \\
\hline $\mathrm{AUC}_{0-t}(\mathrm{~h} * \mathrm{ng} / \mathrm{mL}), n$ & $1768(67.1), 10$ \\
\hline $\mathrm{AUC}_{0 \text {-tau }}(\mathrm{h} * \mathrm{ng} / \mathrm{mL}), n$ & 1958 (61.9), 9 \\
\hline$C_{\max }(\mathrm{ng} / \mathrm{mL}), n$ & $17.73(176.1), 10$ \\
\hline$t_{1 / 2}(\mathrm{~h}), n$ & $91.64(7.8), 5$ \\
\hline$T_{\max }(\mathrm{h})^{\mathrm{a}}, n$ & $36.10(3.95,72.37), 10$ \\
\hline \multicolumn{2}{|l|}{ Week $11 / 12$} \\
\hline$A \cup C_{0 \text {-inf }}(\mathrm{h} * \mathrm{ng} / \mathrm{mL}), n$ & $5358(16.3), 5$ \\
\hline $\mathrm{AUC}_{0-t}(\mathrm{~h} * \mathrm{ng} / \mathrm{mL}), n$ & $3452(31.0), 10$ \\
\hline $\mathrm{AUC}_{0 \text {-tau }}(\mathrm{h} * \mathrm{ng} / \mathrm{mL}), n$ & 3546 (31.8), 8 \\
\hline$C_{\max }(\mathrm{ng} / \mathrm{mL}), n$ & $32.35(72.2), 10$ \\
\hline$t_{1 / 2}(\mathrm{~h}), n$ & $101.3(41.3), 5$ \\
\hline$T_{\max }(\mathrm{h})^{\mathrm{a}}, n$ & $35.53(1.92,73.53), 10$ \\
\hline
\end{tabular}

$\mathbf{0 . 3} \mathbf{~ m g / k g ~ G X - H 9 ~ E O W ~}(n=11)$
$15970(55.6), 10$
$12250(68.5), 11$
$13810(62.2), 10$
$120.4(96.9), 11$
$105.3(43.2), 10$
$24.00(3.95,72.63), 11$
$18270(62.3), 9$
$14460(72.3), 11$
$15750(68.3), 10$
$110.0(111.8), 11$
$97.39(25.4), 9$
$48.00(12.00,169.00), 11$

$0.2 \mathrm{mg} / \mathrm{kg}$ GX-H9 EOW $(n=11)$

$6377(27.4), 11$

$5776(27.2), 11$

$5815(27.4), 11$

$59.40(96.0), 11$

$89.66(24.6), 11$

$12.00(4.00,71.95), 11$

8040 (30.8), 11

7191 (27.8), 11

7192 (27.8), 11

63.98 (80.6), 11

$98.11(25.9), 11$

$12.00(8.00,48.00), 11$

${ }^{\mathrm{a}}$ For $T_{\text {max }}$ the median (minimum, maximum) values are presented.

$\mathrm{AUC}_{0 \text {-inf }}$ area under the serum concentration-time curve from time zero to infinity; $\mathrm{AUC}_{0 \text {-t }}$ area under the serum concentration-time curve from time 0 to the last measurable concentration, $\mathrm{AUC}_{0 \text {-taur }}$ area under the serum concentration-time curve over a dosing interval; $C_{\text {max }}$ observed maximum serum concentration; EOW, every other week; $N$, number of subjects; $t_{1 / 2}$, terminal phase half-life; $T_{\max }$, time to observed maximum concentration. 

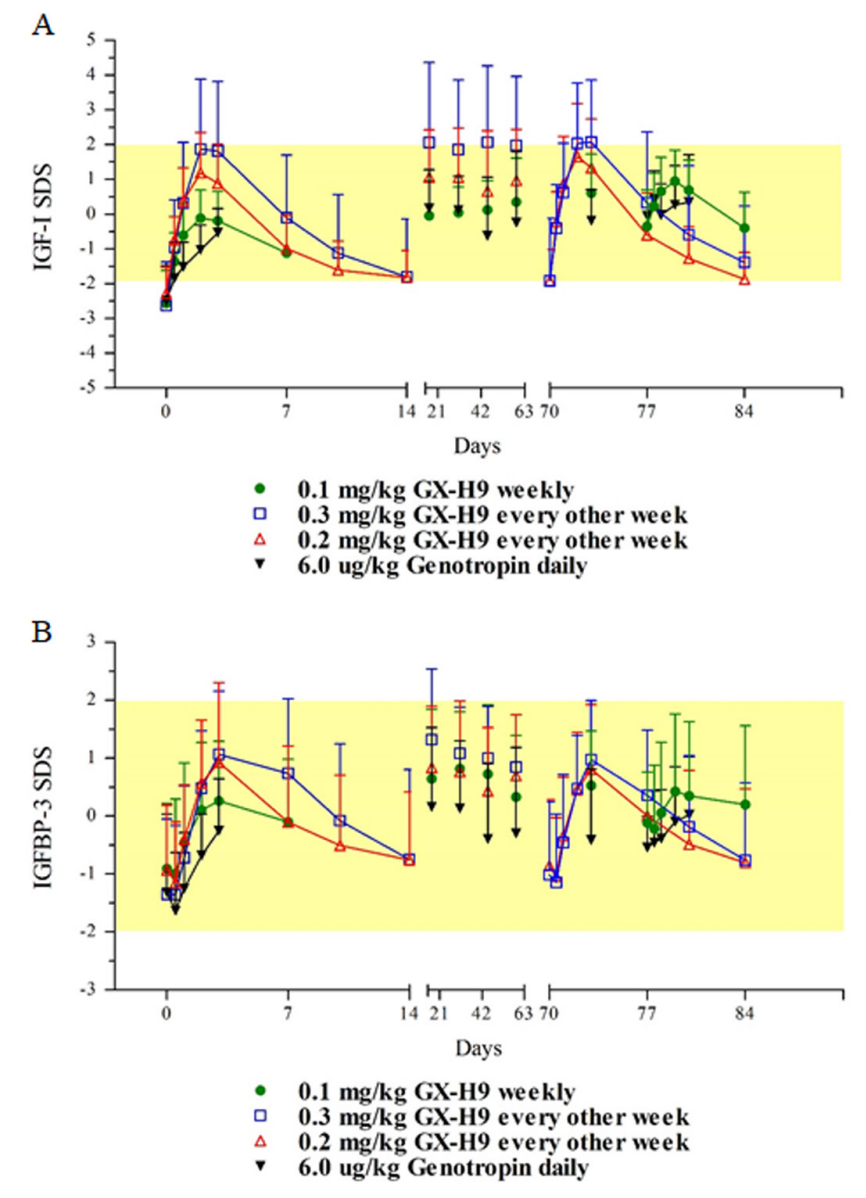

Figure 3

Changes in IGF-I and IGFBP-3 SDS in the per-protocol set. The data are expressed as means \pm standard deviations with linear scales. (A) IGF-I SDS are shown, and (B) IGFBP-3 SDS are shown. Yellow boxes indicate a range of \pm 2 SDS. IFGBP-3, IGF-binding protein 3; IGF-I, insulin-like growth factor I; SDS, standard deviations.

\section{Subject analysis sets}

The analysis sets were defined according to the following parameters. (1) All screened set: included all subjects who signed an informed consent form and attended screening, regardless of randomization. (2) Intent-totreat (ITT) set: included all subjects who received at least one dose of study drug in the treatment period. The ITT analysis set was used for demographic/baseline characteristics and efficacy endpoints. (3) Per-protocol (PP) set: included all subjects in the ITT analysis set without important protocol deviations. The PP analysis set was the population for the pharmacokinetic and efficacy analysis. (4) Safety set: included all subjects with at least one post-baseline safety assessment and who received at least one dose of study drug. The safety set was used for all safety analyses.

\section{Statistical analysis}

All analyses were conducted using SAS software (SAS Institute, Inc.) version 9.2. No formal statistical sample size calculations were made, attributable to the exploratory nature of this Phase $1 \mathrm{~b} / 2$ study. The study size of 15 subjects per group was considered sufficient to assess the endpoints of the study. The primary efficacy analysis model was a mixed model for repeated measures (MMRM). The MMRM model analyzed the mean percent change from baseline (CFB) of standardized IGF-I at Weeks 1, 3, 5, 7, 9 and 11 (72h after dosing), with baseline standardized IGF-I score, visit, treatment and treatment by visit interactions included in the model. An analysis of covariance (ANCOVA) model was used to assess differences in the secondary efficacy endpoints (lipid parameters, waist circumference, hip circumference, waist-to-hip ratio and BMI) at Week 11/12 among treatment groups. An ANCOVA model with treatment group as a fixed effect and log-transformed baseline value as a covariate was used to separately assess differences in $\mathrm{AUC}_{0-t}$ and $C_{\max }$ of IGF-I and IGFBP-3 between the GX-H9 treatment groups and the active comparator (Genotropin) at the first and last dose. A two-sided 5\% significance level was used for all statistical inferences.

\section{Results}

\section{Patient disposition}

A total of 45 GHD adult subjects were enrolled in the study. In the $0.1 \mathrm{mg} / \mathrm{kg}$ GX-H9 weekly treatment group, $1(8.3 \%)$ subject discontinued prior to receiving any treatment, attributable to being ineligible for study participation and 11 (91.7\%) subjects completed the study. In the $0.3 \mathrm{mg} / \mathrm{kg}$ GX-H9 EOW and $0.2 \mathrm{mg} / \mathrm{kg}$ GX-H9 EOW treatment groups, all subjects completed the study. Out of nine subjects assigned to the $6 \mu \mathrm{g} / \mathrm{kg}$ Genotropin daily treatment group, $2(22.2 \%)$ subjects discontinued the study; one subject discontinued because of elevations in hepatic enzymes and the other because of the possibility of an abdominal malignancy that was found post dosing, but may have been present beforehand. The remaining 7 (77.8\%) subjects completed the study (Supplementary Fig. 1, see section on supplementary data given at the end of this article). Baseline characteristics were similar across 
Table 4 Serum pharmacodynamic geometric mean parameters of IGF-I changes from baseline (per-protocol set).

\begin{tabular}{|c|c|c|c|c|c|}
\hline Analyte & Parameter (unit) & $\begin{array}{c}0.1 \text { mg/kg GX-H9 } \\
\text { weekly }(n=10)\end{array}$ & $\begin{array}{c}\mathbf{0 . 3} \mathbf{~ m g} / \mathbf{k g} \mathbf{~ G X - H 9} \\
\text { EOW }(n=11)\end{array}$ & $\begin{array}{c}0.2 \mathbf{~ m g} / \mathbf{k g} \text { GX-H9 } \\
\text { EOW }(n=11)\end{array}$ & $\begin{array}{c}\mathbf{6} \boldsymbol{\mu g} / \mathbf{k g} \text { Genotropin } \\
\text { daily }(n=7)\end{array}$ \\
\hline \multirow[t]{5}{*}{ IGF-I } & Week 1 & & & & \\
\hline & Delta $A \cup C_{0-t}(h * n g / m L)$ & $9149.2(35.6)$ & $25044.2(52.2)$ & $14827.7(40.1)$ & $2247.6(41.6)$ \\
\hline & $\begin{array}{l}\text { Delta } C_{\max }(\mathrm{ng} / \mathrm{mL}) \\
\text { Week } 11 / 12\end{array}$ & $75.1(38.9)$ & $155.1(52.0)$ & 109.8 (33.9) & $34.6(55.6)$ \\
\hline & Delta $A \cup C_{0-t}(\mathrm{~h} * \mathrm{ng} / \mathrm{mL})$ & $14867.8(45.4)$ & $30047.4(47.7)$ & $18217.4(42.9)$ & $6391.8(13.9)$ \\
\hline & Delta $C_{\max }(\mathrm{ng} / \mathrm{mL})$ & $115.0(44.0)$ & $172.4(46.3)$ & $127.9(42.4)$ & $97.3(9.6)$ \\
\hline \multirow[t]{6}{*}{ IGFBP3 } & Week 1 & & & & \\
\hline & Delta $A \cup C_{0-t}(h * n g / m L)$ & $100712.1(53.9)$ & $427445.3(41.0)$ & $199792.0(64.6)$ & $31260.2(59.2)$ \\
\hline & Delta $C_{\max }(\mathrm{ng} / \mathrm{mL})$ & $1008.3(45.0)$ & $2171.9(31.6)$ & $1538.6(42.2)$ & $256.8(76.5)$ \\
\hline & Week $11 / 12$ & & & & \\
\hline & Delta $\mathrm{AUC}_{0-t}(\mathrm{~h} * \mathrm{ng} / \mathrm{mL})$ & $140061.2(64.0)$ & $347735.8(47.9)$ & $197526.5(55.4)$ & $62963.5(69.6)$ \\
\hline & Delta $C_{\max }(\mathrm{ng} / \mathrm{mL})$ & $1093.7(61.8)$ & $1777.6(46.4)$ & $1515.2(21.1)$ & $609.5(67.2)$ \\
\hline
\end{tabular}

Values are presented with the coefficient of variation in parentheses. Week $110.3 \mathrm{mg} / \mathrm{kg} \mathrm{GX}-\mathrm{H} 9$ and $0.2 \mathrm{mg} / \mathrm{kg}$ GX-H9 parameters were compared with Week $120.1 \mathrm{mg} / \mathrm{kg}$ GX-H9 and $6 \mu \mathrm{g} / \mathrm{kg}$ daily parameters. Delta $C_{\max }$ and Delta $A \cup C_{0-t}$ were calculated based on the changes from baseline concentrations. $A \cup C_{0-t}$, area under the serum concentration-time curve from time 0 to the last measurable concentration; $C_{\max }$ observed maximum serum concentration; EOW, every other week; IGF-I, insulin-like growth factor 1; IGFBP-3, IGF binding protein-3; $N$, number of subjects.

treatment groups, except for race, despite the limited sample size (Table 1).

\section{Primary endpoint: change in IGF-I S.D. score from baseline}

For the PP set, there were no statistically significant least squares (LS) mean differences in IGF-I s.D. score at Weeks 1, 3, 5, 7, 9 and 11 (72h post dose) between the GX-H9 treatment groups and $6 \mu \mathrm{g} / \mathrm{kg}$ Genotropin treatment group $(P>0.05)$, except for the $0.3 \mathrm{mg} / \mathrm{kg}$ GX-H9 EOW vs $6 \mu \mathrm{g} / \mathrm{kg}$ Genotropin daily treatment groups at Week 1 (72h post dose) $(P=0.023)$. Results of the ITT set were similar to those of the PP set (Table 2).

\section{Secondary efficacy endpoints: lipid parameters, waist/hip circumference and BMI}

For the PP set, there were no statistically significant differences in LS means for lipids (high-density lipoprotein cholesterol (HDL-C), low-density lipoprotein cholesterol (LDL-C), lipoprotein alpha, total cholesterol and triglycerides), waist circumference, hip circumference, waist-to-hip ratio and BMI at Week 12 between the GX-H9 treatment groups and $6 \mu \mathrm{g} / \mathrm{kg}$ Genotropin treatment group $(P>0.05)$ (Supplementary Table 1$)$. Results of the ITT set were similar to those of the PP set.

\section{Safety}

A summary of adverse events (AEs) is provided in Supplementary Table 2. Overall, 45.5, 75.0, 50.0 and
$77.8 \%$ of subjects experienced a total of 12, 20, 10 and 8 treatment-emergent adverse events (TEAEs) in the $0.1 \mathrm{mg} / \mathrm{kg}$ GX-H9 weekly, $0.3 \mathrm{mg} / \mathrm{kg}$ GX-H9 EOW, $0.2 \mathrm{mg} /$ $\mathrm{kg}$ GX-H9 EOW and $6 \mu \mathrm{g} / \mathrm{kg}$ Genotropin daily treatment groups respectively. TEAEs reported by $>1$ subject in any treatment group included headache, nasopharyngitis and increased blood creatinine phosphokinase. There was one TEAE (elevated hepatic enzymes) that led to treatment discontinuation in the Genotropin group. None of the subjects experienced severe TEAEs. Finally, no treatment-emergent antidrug antibodies (ADA) were detected during the study. Overall, the incidence and profile of AEs observed in the GX-H9 groups were comparable to those in patients receiving daily rhGH (Genotropin).

\section{Pharmacokinetics}

After administration of a single SC dose of GX-H9 in Week 1, a dose-dependent increase in mean peak GX-H9 and total exposure $\left(C_{\max }\right.$ and AUC) was observed. However, when comparing GX-H9 concentrations at Week 1 with those at Week 11/12, little accumulation was observed (Fig. 2). Concentrations were much higher for the $0.3 \mathrm{mg} / \mathrm{kg}$ EOW dosage than for the other treatments. GX-H9 reached mean peak plasma levels across treatment groups in approximately $24 \mathrm{~h}$ during Week 1 and Week 11/12 (Table 3). Furthermore, total exposure $\left(\mathrm{AUC}_{0-t}\right)$ of $\mathrm{GX}-\mathrm{H} 9$ in subjects treated with $0.3 \mathrm{mg} / \mathrm{kg}$ EOW was approximately four-fold higher than that in subjects treated with $0.1 \mathrm{mg} / \mathrm{kg}$ every week, and an increase in exposure that was more than 
proportional to the increased dose was observed at the end of the 3-month dosing period. However, the small sample size per group limited estimates of accurate correlations that may have existed among demographic characteristics and GX-H9 PK parameters.

\section{Pharmacodynamics: IGF-I and IGFBP-3 kinetics}

IGF-I levels increased significantly following administration of $0.1 \mathrm{mg} / \mathrm{kg}$ GX-H9 weekly, $0.3 \mathrm{mg} / \mathrm{kg}$ and $0.2 \mathrm{mg} / \mathrm{kg}$ GX-H9 EOW and $6 \mu \mathrm{g} / \mathrm{kg}$ Genotropin daily SC, with the highest mean levels achieved approximately $48-72 \mathrm{~h}$ after dosing (Fig. 3). The mean IGF-I response was sustained above baseline over the intended dose interval of $168 \mathrm{~h}$ for the $0.1 \mathrm{mg} / \mathrm{kg}$ GX-H9 weekly dosage group and $336 \mathrm{~h}$ for the 0.2 and $0.3 \mathrm{mg} / \mathrm{kg}$ GX-H9 EOW dosage groups.

IGF-I levels $72 \mathrm{~h}$ after dosing were relatively constant on the weeks sampled throughout the 12-week dosing period for all treatment groups (Table 4). Similar changes were also observed for IGFBP-3.

\section{Discussion}

GX-H9 is a novel, extended, long-acting rhGH fused to hyFc intended to reduce the frequency of administration, thereby enhancing treatment compliance while providing efficacy comparable to that of commercially available daily rhGH treatments. In this study, the authors present results of a Phase $1 \mathrm{~b} / 2$ randomized study in AGHD patients.

In the previous first-in-human, double-blind, randomized, placebo-controlled, single ascending dose study of GX-H9 in healthy subjects (Phase 1, EudraCT No. 2013-002771-18), safety and tolerability, as well as PK and PD profiles were investigated. In a group consisting of 31 healthy male participants who completed the study, single SC doses of GX-H9 ranging from 0.2 to $1.6 \mathrm{mg} / \mathrm{kg}$ were safe and well tolerated (GX-H9-001 clinical study report, unpublished data). Because there were dose-dependent correlations between PK and PD profiles from the Phase 1 study even at lower doses and AGHD patients were relatively sensitive to GH replacement in other clinical studies $(6,16)$, we decided to begin administration of GX-H9 at $0.1 \mathrm{mg} / \mathrm{kg}$ weekly for this Phase $1 \mathrm{~b} / 2$ study and then escalate the dosage to $0.3 \mathrm{mg} / \mathrm{kg}$ EOW, $0.3 \mathrm{mg} /$ $\mathrm{kg}$ weekly and then $0.6 \mathrm{mg} / \mathrm{kg}$ EOW. However, after gathering PK, PD and safety data from the $0.1 \mathrm{mg} / \mathrm{kg}$ weekly and $0.3 \mathrm{mg} / \mathrm{kg}$ EOW GX-H9 groups, the sponsor and members of the SMC agreed to use $0.2 \mathrm{mg} / \mathrm{kg}$ EOW for Group 3 rather than proceed with the planned dosage regimen of $0.3 \mathrm{mg} / \mathrm{kg}$ weekly and then $0.6 \mathrm{mg} / \mathrm{kg}$ EOW because significant increments in IGF-I were observed in the $0.3 \mathrm{mg} / \mathrm{kg}$ EOW GX-H9 group.

Serum IGF-I levels are a valid surrogate marker for rhGH activity (12). In this study, changes in IGF-I levels post dosing were set as the primary endpoint. IGF-I levels were normalized, and the IGF-I S.D. score reached the target range ( -2 SDS to +2 SDS) in all treatment groups. There were no statistically significant LS mean differences in IGF-I s.D. scores at Weeks 1, 3, 5, 7, 9 and 11 (72 h post dose) between the GX-H9 treatment groups and the $6 \mu \mathrm{g} /$ $\mathrm{kg}$ Genotropin treatment group. Furthermore, mean IGF-I SDS values did not exceed the physiological range $(-2$ SDS to +2 SDS) for most of the study, except for transient increments during several hours after drug administration. Unlike daily injections, a larger volume of a long-acting agent should be injected at one time. Thus, transient elevations in IGF-I for several hours after administration are observed for other long-acting therapeutics (17). The trending increase in IGF-I SDS levels was comparable for both GX-H9 and Genotropin after treatment for 12 weeks; these results are similar to those of other studies $(6,7$, $18,19)$. Mean fasting morning glucose levels remained within the normal range for the 12 weeks of treatment; no hypoglycemia was observed. Glucose impairment was not aggravated in any of the treatment groups. In general, there were no clinically meaningful CFBs or apparent differences in glucose parameters across treatment groups.

There was a single event of lipohypertrophy in the $0.2 \mathrm{mg} / \mathrm{kg}$ GX-H9 EOW group, which has also been reported in GHD patients receiving other weekly GH replacement $(20,21)$; this event was thought to be caused by an inappropriate injection-site rotation, and the patient recovered within a week during the continuous GX-H9 injections. Overall, the clinical and laboratory results showed no clinically relevant or significant findings. Furthermore, no patients developed treatment-emergent anti-GX-H9 antibodies.

There are several limitations to this study. First, all participants of the $0.1 \mathrm{mg} / \mathrm{kg}$ GX-H9 weekly group consisted of Asian subjects because only patients within the Korean institutes were enrolled. However, there were no racial differences in the other treatment groups, including the 0.3 and $0.2 \mathrm{mg} / \mathrm{kg}$ EOW and Genotropin daily injection groups. Second, there were no significant changes in metabolic parameters, including lipid profiles, BMI and waist-to-hip ratio after 12 weeks of GX-H9 or Genotropin treatment. The relatively short duration of rhGH replacement could explain this result. Three months have been shown to be adequate to evaluate the 
efficacy of rhGH therapeutics in GHD patients based on changes in IGF-I or IGFBP-3 (12); however, most clinical studies demonstrate the positive effects of rhGH on metabolic parameters after a minimum of 6 months of treatment $(22,23)$. Finally, the study group was too small to generalize the efficacy and safety of GX-H9, attributable to the limitations of a Phase 2 clinical study. However, a Phase 3 study is planned with a longer treatment period and more patients to establish the clinical outcomes of GX-H9.

In this study, GX-H9 was safe and well tolerated without significant safety concern, warranting further clinical development in patients with AGHD. The safety profile observed in this study was similar to the profile observed in other studies $(24,25)$. GX-H9 effectively increased IGF-I levels, and the IGF-I S.D. score reached its target range in all treatment groups. There were no significant LS mean differences in IGF-I S.D. score between the GX-H9 once weekly or EOW and Genotropin daily groups. Furthermore, an increase in total exposure $\left(\mathrm{AUC}_{0-\mathrm{t}}\right.$ ) of $\mathrm{GX}-\mathrm{H} 9$ that was disproportional to the increase in dose was observed at the end of the 3-month dosing period. Overall, the present study shows that GX-H9 has the potential for up to twicemonthly treatment in AGHD patients.

\section{Supplementary data}

This is linked to the online version of the paper at https://doi.org/10.1530/ EJE-18-0185.

\section{Declaration of interest}

Y J C is an employee and stakeholder of Handok. S J H is an employee of Handok. $\mathrm{M} \mathrm{H}$ is an employee and stakeholder of Genexine. T K K is a former employee and $J \mathrm{~L}$ is an employee of Genexine.

\section{Funding}

The trial was financially supported by Handok and Genexine Inc. This study was supported by Korea Drug Development Fund (http://www.kddf. org) funded by a consortium of three health-related Korean Ministries the Ministry of Science, ICT, and Future Planning; the Ministry of Trade, Industry, and Energy and the Ministry of Health and Welfare (KDDF201502-11: Global Phase 2 study (AGHD) of next generation human growth hormone drug (GX-H9) in EU/KR and Approval of PGHD trial in EU).

\section{Author contribution statement}

$E J L$ and $T K K$ designed the study, and $J L$ and $S J H$ were responsible for conducting the research. CR K, T B, K S, S I, S M, Y C, B K, K Y H, H K, J H K, $M S K, A K, M B, M R, S D$, JP and $E J L$ recruited the patients and provided medical care in compliance with the protocol. $\mathrm{M} \mathrm{H}$ and $\mathrm{Y} \mathrm{J} \mathrm{C} \mathrm{contributed} \mathrm{to}$ the design, figures and interpretation of the results. $C R K$ took the lead in writing the manuscript. C R K, Y J C, S J H, T K K, M H, and J L took part in the writing and final editing of the report. $E J L$ had primary responsibility for the final content. All the authors read and approved the final version.

\section{References}

1 Hazem A, Elamin MB, Bancos I, Malaga G, Prutsky G, Domecq JP, Elraiyah TA, Abu Elnour NO, Prevost Y, Almandoz JP et al. Body composition and quality of life in adults treated with GH therapy: a systematic review and meta-analysis. European Journal of Endocrinology 2012166 13-20. (https://doi.org/10.1530/EJE-11-0558)

2 Carroll PV, Christ ER, Bengtsson BA, Carlsson L, Christiansen JS, Clemmons D, Hintz R, Ho K, Laron Z, Sizonenko P et al. Growth hormone deficiency in adulthood and the effects of growth hormone replacement: a review. Growth Hormone Research Society Scientific Committee. Journal of Clinical Endocrinology and Metabolism $1998 \mathbf{8 3}$ 382-395. (https://doi.org/10.1210/jcem.83.2.4594)

3 Kim SY. Diagnosis and treatment of hypopituitarism. Endocrinology and Metabolism 201530 443-455. (https://doi.org/10.3803/ EnM.2015.30.4.443)

4 Baum HB, Biller BM, Finkelstein JS, Cannistraro KB, Oppenhein DS, Schoenfeld DA, Michel TH, Wittink H \& Klibanski A. Effects of physiologic growth hormone therapy on bone density and body composition in patients with adult-onset growth hormone deficiency. A randomized, placebo-controlled trial. Annals of Internal Medicine 1996125 883-890. (https://doi.org/10.7326/0003-4819125-11-199612010-00003)

5 Reed ML, Merriam GR \& Kargi AY. Adult growth hormone deficiency - benefits, side effects, and risks of growth hormone replacement. Frontiers in Endocrinology 20134 64. (https://doi.org/10.3389/ fendo.2013.00064)

6 Rasmussen MH, Janukonyté J, Klose M, Marina D, Tanvig M, Nielsen LF, Höybye C, Andersen M, Feldt Rasmussen U \& Christiansen JS. Reversible albumin-binding GH possesses a potential once-weekly treatment profile in adult growth hormone deficiency. Journal of Clinical Endocrinology and Metabolism 2016101 988-998. (https://doi.org/10.1210/jc.2015-1991)

7 Höybye C, Pfeiffer AF, Ferone D, Christiansen JS, Gilfoyle D, Christoffersen ED, Mortensen E, Leff JA \& Beckert M. A phase 2 trial of long-acting TransCon growth hormone in adult GH deficiency. Endocrine Connections 20176 129-138. (https://doi.org/10.1530/ EC-17-0007)

8 Christiansen JS, Backeljauw PF, Bidlingmaier M, Biller BM, Boguszewski MC, Casanueva F, Chanson P, Chatelain P, Choong CS, Clemmons DR et al. Growth Hormone Research Society perspective on the development of long-acting growth hormone preparations. European Journal of Endocrinology 2016174 C1-C8. (https://doi. org/10.1530/EJE-16-0111)

9 Liu XY, Pop LM \& Vitetta ES. Engineering therapeutic monoclonal antibodies. Immunological Reviews 2008222 9-27. (https://doi. org/10.1111/j.1600-065X.2008.00601.x)

10 Presta LG. Selection, design, and engineering of therapeutic antibodies. Journal of Allergy and Clinical Immunology 2005116 731-736; quiz 737. (https://doi.org/10.1016/j.jaci.2005.08.003)

11 Im SJ, Yang SI, Choi DH, Choi SY, Kim HS, Jang DS, Jin KS, Chung Y, Kim S, Paik SH et al. Natural form of noncytolytic flexible human Fc as a long-acting carrier of agonistic ligand, erythropoietin. PLOS ONE 20116 e24574. (https://doi.org/10.1371/journal.pone.0024574)

12 Molitch ME, Clemmons DR, Malozowski S, Merriam GR \& Vance ML. Evaluation and treatment of adult growth hormone deficiency: an Endocrine Society Clinical Practice Guideline. Journal of Clinical Endocrinology and Metabolism 201196 1587-1609. (https://doi. org/10.1210/jc.2011-0179)

13 Shankar G, Devanarayan V, Amaravadi L, Barrett YC, Bowsher R, Finco-Kent D, Fiscella M, Gorovits B, Kirschner S, Moxness M et al. Recommendations for the validation of immunoassays used for detection of host antibodies against biotechnology products. Journal of Pharmaceutical and Biomedical Analysis 200848 1267-1281. (https://doi.org/10.1016/j.jpba.2008.09.020) 
14 Center for Drug Evaluation, Research \& Center for Veterinary Medicine. Guidance for Industry: Bioanalytical Method Validation. Revision 1. Rockville, MD: U.S. Department of Health and Human Services, Food and Drug Administration, Center for Drug Evaluation and Research (CDER), Center for Veterinary Medicine (CVM), 2013.

15 Bidlingmaier M, Friedrich N, Emeny RT, Spranger J, Wolthers OD, Roswall J, Körner A, Obermayer Pietsch B, Hübener C, Dahlgren J et al. Reference intervals for insulin-like growth factor-1 (igf-i) from birth to senescence: results from a multicenter study using a new automated chemiluminescence IGF-I immunoassay conforming to recent international recommendations. Journal of Clinical Endocrinology and Metabolism 201499 1712-1721. (https://doi. org/10.1210/jc.2013-3059)

16 Rasmussen MH, Olsen MW, Alifrangis L, Klim S \& Suntum M. A reversible albumin-binding growth hormone derivative is well tolerated and possesses a potential once-weekly treatment profile. Journal of Clinical Endocrinology and Metabolism 201499 E1819-E1829. (https://doi.org/10.1210/jc.2014-1702)

17 Astruc B, Marbach P, Bouterfa H, Denot C, Safari M, Vitaliti A \& Sheppard M. Long-acting octreotide and prolonged-release lanreotide formulations have different pharmacokinetic profiles. Journal of Clinical Pharmacology 200545 836-844. (https://doi. org/10.1177/0091270005277936)

18 Desrosiers P, O'Brien F \& Blethen S. Patient outcomes in the GHMonitor: the effect of delivery device on compliance and growth. Pediatric Endocrinology Reviews 20052 (Supplement 3) 327-331.

19 Svensson J \& Johannson G. Long-term efficacy and safety of somatropin for adult growth hormone deficiency. Treatments in Endocrinology 20032 109-120. (https://doi.org/10.2165/00024677200302020-00004)

20 Touraine P, D'Souza GA, Kourides I, Abs R, Barclay P, Xie R, Pico A, Torres Vela E \& Ekman B. Lipoatrophy in GH deficient patients treated with a long-acting pegylated GH. European Journal of Endocrinology 2009161 533-540. (https://doi.org/10.1530/ EJE-09-0422)

21 Strasburger CJ, Vanuga P, Payer J, Pfeifer M, Popovic V, Bajnok L, Góth M, Olšovská V, Trejbalová L, Vadasz J et al. MOD-4023, a longacting carboxy-terminal peptide-modified human growth hormone: results of a Phase 2 study in growth hormone-deficient adults. European Journal of Endocrinology 2017176 283-294. (https://doi. org/10.1530/EJE-16-0748)

22 Kim Y, Hong JW, Chung Y, Kim S, Cho Y, Kim JH, Kim B \& Lee EJ. Efficacy and safety of sustained-release recombinant human growth hormone in Korean adults with growth hormone deficiency. Yonsei Medical Journal 201455 1042-1048. (https://doi.org/10.3349/ ymj.2014.55.4.1042)

23 Biller BM, Ji H, Ahn H, Savoy C, Siepl EC, Popovic V, Coculescu M, Roemmler J, Gavrila C, Cook DM et al. Effects of once-weekly sustained-release growth hormone: a double-blind, placebocontrolled study in adult growth hormone deficiency. Journal of Clinical Endocrinology and Metabolism 201196 1718-1726. (https:// doi.org/10.1210/jc.2010-2819)

24 Yuen KC, Conway GS, Popovic V, Merriam GR, Bailey T, Hamrahian AH, Biller BM, Kipnes M, Moore JA, Humphriss E et al. A long-acting human growth hormone with delayed clearance (VRS-317): results of a double-blind, placebo-controlled, single ascending dose study in growth hormone-deficient adults. Journal of Clinical Endocrinology and Metabolism 201398 2595-2603. (https:// doi.org/10.1210/jc.2013-1437)

25 Biller BM, Ji H, Ahn H, Savoy C, Siepl EC, Popovic V, Coculescu M, Roemmler J, Gavrila C, Cook DM et al. 12-month effects of onceweekly sustained-release growth hormone treatment in adults with GH deficiency. Pituitary 201316 311-318. (https://doi.org/10.1007/ s11102-012-0422-8)

Received 5 March 2018

Revised version received 18 June 2018

Accepted 3 July 2018 